\title{
Resource and Energy Saving Neural Network-Based Control Approach for Continuous Carbon Steel Pickling Process
}

\author{
Oleksandr Bezsonov', Oleg Ilyunin ${ }^{* 2}$, Botagoz Kaldybaeva ${ }^{3}$, Oleksandr Selyakov ${ }^{4}$, \\ Oleksandr Perevertaylenko ${ }^{5}$, Alisher Khusanov ${ }^{6}$, Oleg Rudenko $^{7}$, Serhiy Udovenko ${ }^{8}$, \\ Anatolij Shamraev ${ }^{9}$, Viktor Zorenko ${ }^{10}$ \\ ${ }^{1}$ Department of Electronic Computer, Kharkiv National University of Radioelectronics, Nauki Ave., 14, \\ UA-61000, Kharkiv, Ukraine \\ e-mail: o.bezsonov@gmail.com
}

${ }^{2}$ Department of Electronic Computer, Kharkiv National University of Radioelectronics, Nauki Ave., 14,

UA-61000, Kharkiv, Ukraine e-mail: khioo@ukr.net

${ }^{3}$ M. Auezov South Kazakhstan State University, Tauke Khan St., KZ-160012, Shymkent,

Republic of Kazakhstan

e-mail: kaldybaeva.b@mail.ru

${ }^{4}$ Department of Electronic Computer, Kharkiv National University of Radioelectronics, Nauki Ave., 14,

UA-61000, Kharkiv, Ukraine

e-mail: alexselyakov11@gmail.com

${ }^{5}$ Department of Integrated Technologies \& Energy Saving, National Technical University

"Kharkiv Polytechnical Institute", Kyrpychova St., 2, UA-61002, Kharkiv, Ukraine e-mail: pvrt@ukr.net

${ }^{6}$ M. Auezov South Kazakhstan State University, Tauke Khan St., KZ-160012, Shymkent,

Republic of Kazakhstan

e-mail: khusanov_1975@inbox.ru

${ }^{7}$ Department of Information Systems, S. Kuznets Kharkiv National University of Economics, Nauki Ave.,

9A, UA-61001, Kharkiv, Ukraine

e-mail: ro590@yahoo.de

${ }^{8}$ Department of Informatics and Computer Technology, S. Kuznets Kharkiv National University of Economics, Nauki Ave., 9A, UA-61001, Kharkiv, Ukraine e-mail: serhiy.udovenko@hneu.net

${ }^{9}$ Department of Software Engineering for Computers and Computer-based Systems, Belgorod State

Technological University named after V.G. Shukhov, Kostyukova St., 46, RU-308012, Belgorod,

Russian Federation

e-mail: shamraev@bsu.edu.ru

${ }^{10}$ Department of Integrated Technologies \& Energy Saving, National Technical University

"Kharkiv Polytechnical Institute", Kyrpychova St., 2, UA-61002, Kharkiv, Ukraine

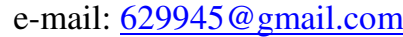

Cite as: Bezsonov, O., Ilyunin, O., Kaldybaeva, B., Selyakov, O., Perevertaylenko, O., Khusanov, A., Rudenko, O., Udovenko, S., Shamraev, A., Zorenko, V., Resource and Energy Saving Neural Network-Based Control Approach for

Continuous Carbon Steel Pickling Process, J. sustain. dev. energy water environ. syst., 7(2), pp 275-292, 2019 , DOI: https://doi.org/10.13044/j.sdewes.d6.0249

\section{ABSTRACT}

Steel pickling processes are very important for steelmaking production quality. Pickling process is based on chemical reaction of acidic pickling solution with scale impurities on steel strip surface. In sulfuric acid pickling process together with scale removal. The partial dissolving of steel surface takes place because of sulfuric acid attack takes place.

\footnotetext{
* Corresponding author
} 
Continuous sulfuric acid carbon steel pickling in existing plants is very energy and water consumptive. An innovative approach is proposed for modernization of continuous sulfuric acid pickling process performance. The proposed neural network model may be used to optimize consumption of sulfuric acid, decrease energy consumption, reduce steel losses and, respectively, reduce harmful wastes and emissions from continuous steel pickling lines. This is possible because of quick adaptation of neural network model to changing environment through fast training algorithms. The developed model identifies the temperature necessary to provide the set process rate at the current variable values of the parameters: concentration of sulfuric acid and concentration of ferrous sulfate multi-hydrates in solution and transmits the temperature value as a current task to regulator in each discrete moment of the process. The results of application of the developed neural network, included as a part of the presented process supervisor, prove its efficiency in use for pickling process operational control: steam consumption for pickling process was decreased by $8 \%$, acid consumption for pickling process was decreased by $26 \%$, while the process efficiency and quality remain unaffected.

\section{KEYWORDS}

Pickling solution, Process supervisor, Radial basis function network, Supervised learning.

\section{INTRODUCTION}

The continuous carbon steel pickling process consists in the treatment of steel strip by immersing it in a series of baths with aqueous acid solution. For carbon steel continuous pickling process usually solutions of hydrochloric or sulfuric acid are used as pickling liquor.

Continuous carbon steel sulfuric acid pickling process was widespread in steelmaking in former USSR and now is used in Ukrainian, Russian and Kazakhstan metallurgical plants and plants that were built, for example in Pakistan with Soviet assistance at the end of the 1980's. The information about process parameters of continuous pickling is still restricted and is not available in literature. So, the main source of information was the inspection of appropriate pickling lines in metallurgical plants in Ukraine, Russia and Kazakhstan.

Sulfuric acid pickling results in pickling sludge, a waste product that includes acidic water, iron sulfates, metallic salts and waste acid. Pickling sludge is the most hazardous waste as reported by the Environmental Protection Agency [1]. Continuous carbon steel pickling lines use a large amount of water (up to 12 ton per ton of production) to prepare solution of sulfuric acid as pickling liquor and spent liquor regeneration. In addition, the solutions have to be regenerated in large volumes or dropped into the process water for neutralization with further water treatment and preparation of new fresh solution. All these measures increase the operation, resource and energy costs of the process and also pollute the production areas (acidifies and salts the soil).

The continuous sulfuric acid pickling process of carbon steel is carried out with a pickling line that consists of several pickling baths. The process medium is the pickling solution or pickling liquor which is diluted sulfuric acid. While diluted acid removes the oxides and other impurities it also attacks the steel surface and partially dissolves it. It is very important to control next interrelated process parameters: dwell time of steel in pickling solution $\left(t_{\mathrm{P}}\right)$, restrictions, sulfuric acid concentration $(C)$ and concentration of ferrous sulfate multi-hydrates in solution $\left(C_{\mathrm{n}}\right)$, pickling solution (PS) temperature $(T)$. Presence of ferrous sulfate multi-hydrates in the pickling solution in an amount up to 9 to $16 \%$ and increasing the temperature up to 88 to $95{ }^{\circ} \mathrm{C}$ accelerates the pickling process. But exceeding these limiting parameters leads to process abnormality: the metal surface damages and the pickling solution transits into inoperable state. The perfect control system is the only way in which the pickling process can be economically grounded and provides optimization of resource consumption, minimization of the pickling process cost and appropriate environmental protection. 


\section{NEURAL NETWORK IN CHEMICAL PROCESSES CONTROL}

Chemical processes have been traditionally controlled using linear system analysis even though they are inherently nonlinear processes.

The steel pickling process is complicated and for its proper control it is necessary to overcome such challenges as multivariable relations between variables. Another problem is non-linear behaviour. Artificial Neural Networks (ANN) offer alternative nonlinear model implementation in industrial systems [2].

ANN models are applied to solve a wide range of problems, for example: acid concentration prediction for cold-rolled carbon steel strip pickling process [3], control the process of cellulosic material conversion into sugar [4], identification of rice parboiling process [5], validation of distillation column model [6], and simulation of water activity in freeze drying [7].

The use of ANN models with a high level of success \{ such as Multilayer Perceptron (MLP) and Radial Basis Function Network (RBFN), Adaptive Neuro-fuzzy Inference System (ANFIS) [8], models designed with use of Response Surface Methodology (RSM) [9, 10], Generalized Regression Neural Network (GRNN), Support Vector Machine (SVM) and Extreme Learning Machine (ELM) modelling methods [11]\} in solving chemical processing problems is provided by their sufficient simplicity and satisfactory accuracy.

Usually the neural networks are used in two parts [12]: for processes simulation and for control. A brief comparative review of the ANN models, which are widely applied in the identification and control of the pickling process, is given in [13]. Different ways of neural Models Predictive Control (MPC) embedded in MPC systems were reviewed in [14]. The results for the multiple input-output feed forward neural network models show better performance for the system control than the conventional PI controller and Neural Network Direct Inverse Control (NNDIC) strategy in all cases [15].

Genetic Algorithm (GA) and Particle Swarm Optimization (PSO), RSM combined with ANN, can be used as the main tool to simulate and optimize the processes of metals removal from aqueous solutions [16]. ANN models, combined with GA, show more accurate predictions, improve generalization possibilities, and calculate more optimal conditions for the flow of simulated processes than RSM models [17].

Iterative multistep neural network predictions in MPC based control for Multiple-Input-Multiple-Output (MIMO) chemical processes have been reported [18].

The advantages of ANN are as follows: distributed information processing and the inherent potential for parallel computation. In many cases, when sufficiently rich data are available, they can provide fairly accurate models for nonlinear controls when model equations are not known [19] or only partial state information is available [20]. Due to their parallel processing capability, nonlinearity in nature and their ability to model without a priori knowledge, ANN can be used successfully to capture the dynamics of multivariable nonlinear systems. Various types of neural network consist of the same basic parts: nodes, layers and connections.

The most widespread solutions of these problems are such artificial neural networks as: MLP and RBFN [13]. However, describing complex TP in one large-scale network makes it difficult to debug the model [21], so in practice the decomposition approach is more common when the TP is represented by several interrelated lower-dimensional models. The clear architecture of RBFN (they consist of one layer of neurons) and the use of simple effective algorithms for their training lead to the fact that use of RBFN is more preferable for real-time identification and control tasks. In this work is presented the single-layer architecture RBFN for identification of optimal pickling process parameters that defines operative tasks for the regulation of PS temperature.

The pickling process involves removal of surface oxides (scales) and other contaminants out of steel strip surface by immersion into a series of baths with an 
aqueous solution of sulfuric acid. The highly nonlinear multivariable dynamic of Technological Process (TP) and interaction between baths causes this process to be difficult to control with conventional controllers. Literature review had shown that current researches on the application of ANN models for control lines continuous pickling for steel pickling process carried out for hydrochloric acid pickling only. A multivariable neural network modelling and Radial Basis Function (RBF) neural network model technique are investigated in this paper for application for steel pickling process using sulfuric acid which is commonly applied to Ukrainian steelworks.

\section{PROCEDURE OF NEURAL NETWORK MODEL DESIGN}

The detailed procedures to find the neural network models for the various objects are summarized in Figure 1. Data sets are obtained by appropriate excitation signals selection.

The excitation signals used to create the test data sets for modelling of the neural network are particularly the singleton-points data, measured during the TP. The other part of the input signal sets is generated using pseudo-random procedures within the ranges between singletons of TP parameters with a sampling time of $1 \mathrm{~min}$. Details of the training procedures of nonlinear systems models are explained in [22].

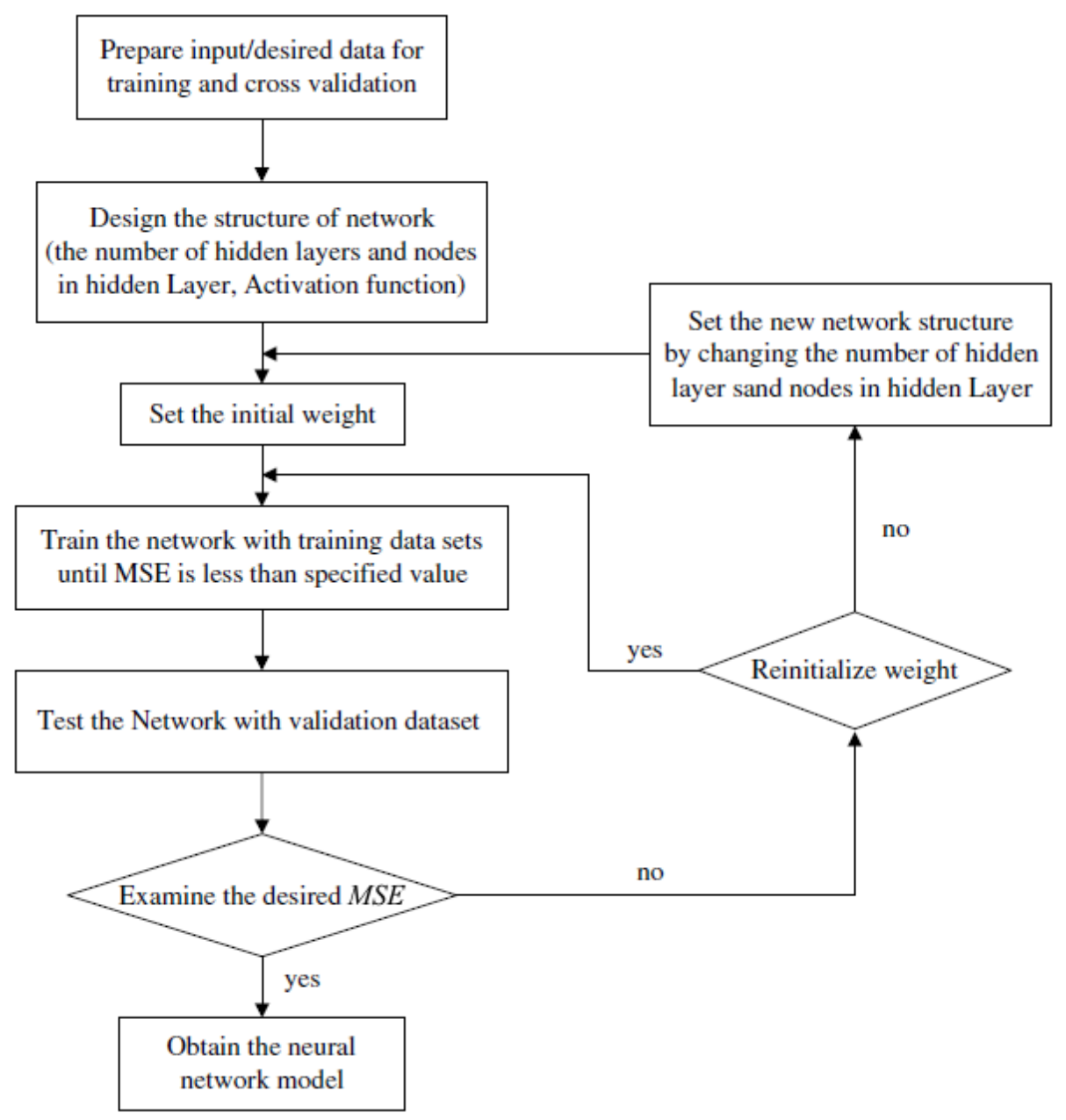

Figure 1. Principle of neural network models design

The data sets need to be scaled in order to overcome the significant minimum and maximum values used in the training process. Process data are scaled down linearly to between 0.05 and 0.95 to avoid obtaining zero outputs and an infinite gain network. In the neural network design suitable neural network structure needs to be selected. 
About $80 \%$ of the generated data set is randomly selected as training data (for the neural network model development), and the remaining $20 \%$ of the data is used to test the networks after training. The important aspects of ANN design are the number of hidden nodes, layers and transfer function used in one.

In this work, the Gaussian functions are used as the activation functions of the nodes in the hidden layer and linear function neurons in its output layer are used. The defined neural networks are trained with the some algorithm, such as Back propagation, Levenberg-Marquardt, Widrow-Hoff, etc., in the Neuroph Studio package, where the common objective is to reduce the error between the neural network predicted value and the actual targeted value. The training is switched between the train and test data and the training stops when the desired Mean Squared Error $(M S E)$ reaches the specified set value. The MSE is expressed mathematically as:

$$
M S E=\frac{1}{n} \sum_{k=1}^{n}\left[y_{\mathrm{tg}}(k)-y_{\mathrm{N}}(k)\right]^{2}
$$

After training, the neural networks are validated by use of the validation data sets. If the validation routine is not satisfactory, the neural network is not properly trained and requires more training. This can be done first by reinitializing the weights and biases and to retrain the neural network for the next loop. Reconfiguring the neural network architecture can also help to increase the quality of the neural network simply by increasing or decreasing of the hidden nodes number. The hidden nodes are varied in various quantities. The MSE error is then monitored and the one that corresponds to the minimum $M S E$ value is selected for determining the final number of hidden nodes. In this work, the optimum structure is selected by the minimum MSE method.

\section{PROCESS PROBLEM ANALYSIS}

During last ten years, large Ukrainian metallurgical enterprises carried out significant modernization of continuous pickling lines to improve their efficiency. A typical pickling line consists of a cascade of 4 baths filled with acid pickling liquor. Set parameters $T$ and $C, C_{\mathrm{n}}$ maintained during TP are presented in the form of a diagram [23].

Defects of the surface of the steel strip are removed by immersion in the baths and then rinsing and scrolling into steel coils.

Existing TP was analyzed on the pickling line at Mariupol Steelworks. There was noted a number of shortcomings: open system of PS heating by steam by its periodical injection into the baths, instability of heating steam parameters and PS respectively. It causes significant perturbations in TP.

Also, there was increased thermal energy consumption due to the need for steam superheating, increased consumption of sulfuric acid and water to maintain the concentration of pickling solution, diluted with condensate of heating steam.

It is necessary also to note the increased load on the solution regeneration station and the amount of waste and sludge exceeding the standards. For these reasons, the technology used did not meet the requirements for energy efficiency and control of emissions to the environment, as established by the directive EC 96/61. To achieve good pickling result and to set scrolling speed of steel strip $(V)$, the condition $\left(\frac{L}{V}-t_{\mathrm{P}}\right) \rightarrow 0$ must be fulfilled, where $L$ is the length of the pickling bath, and $t_{\mathrm{P}} \rightarrow \min$ is specified by the TP regulation to be the same for each of baths. For this, the parameters of the solution $T$ and $C$ in each pickling bath must be kept at a certain level. Determination of the optimum PS parameters depends on the assortment and quality of the rolled strip, the process 
conditions, and the rate of loss of PS activity due to a drop in concentration during pickling of defects which number is of a random quantity.

The speed of pickling, amount of industrial waste, sludge, spent solution that should be regenerated and recycled, depend on two types of process parameters: the first includes the steel composition and structure of scale, the second includes the acid concentration in the solution and its temperature [24].

The next parameter influencing the TP is the acid concentration $C$. The concentration of ferrous sulfate $n^{\circ}$ hydrates in solution $\left(C_{\mathrm{n}}\right)$ primarily is considered as a limiting factor of the solution life time until its complete draining $\left(C_{\mathrm{n}} \leq 16 \%\right)$ or $\left(C_{\mathrm{n}} \leq 6 \%\right)$, partially refreshing [25], but also accelerates the process for certain intervals of $\left(T, C, C_{\mathrm{n}}\right)$ parameters.

The procedure of the TP parameters values identifying for maintaining a constant pickling rate of strip steel can be described with the neural network identification Multiple-Input-Single-Output (MISO) model of the $X \rightarrow Y$ form [26]. The proposed model will help to optimize consumption of sulfuric acid, reduce water consumption for acid regeneration, heat energy consumption and, respectively, emissions of continuous steel pickling lines.

\section{IDENTIFICATION OF OPTIMAL PIKCLING PROCESS STATE}

For sulfuric acid pickling process there are two types of pickling solution heating: the superheated steam direct injection and heating in the remote heat exchangers by solution pumping. Only the second type will be considered below.

\section{Process description}

The steel pickling process consists of two major steps: pickling and rinsing steps [24]. The purpose of the pickling is to remove surface oxides (scale) by an immersion of the steel into an aqueous acid solution. The steel strip passes the cascade of four pickling baths, containing $8-10 \%, 11-12 \%, 13.5-14.5 \%$ and $16.5-17.5 \%$ sulfuric acid solution by Sulfuric acid $\left(\mathrm{H}_{2} \mathrm{SO}_{4}\right)$ weight, respectively.

During retrofit, the method of heating the pickling solution in remote high effective plate heat exchangers - condensers with the stabilization of the individual temperature regimes of the pickling solution for each bath was used. This method is used for pickling with hydrochloric acid solutions [27] or with sulfuric acid solutions and special shell-and-tube graphite heat exchangers [28].

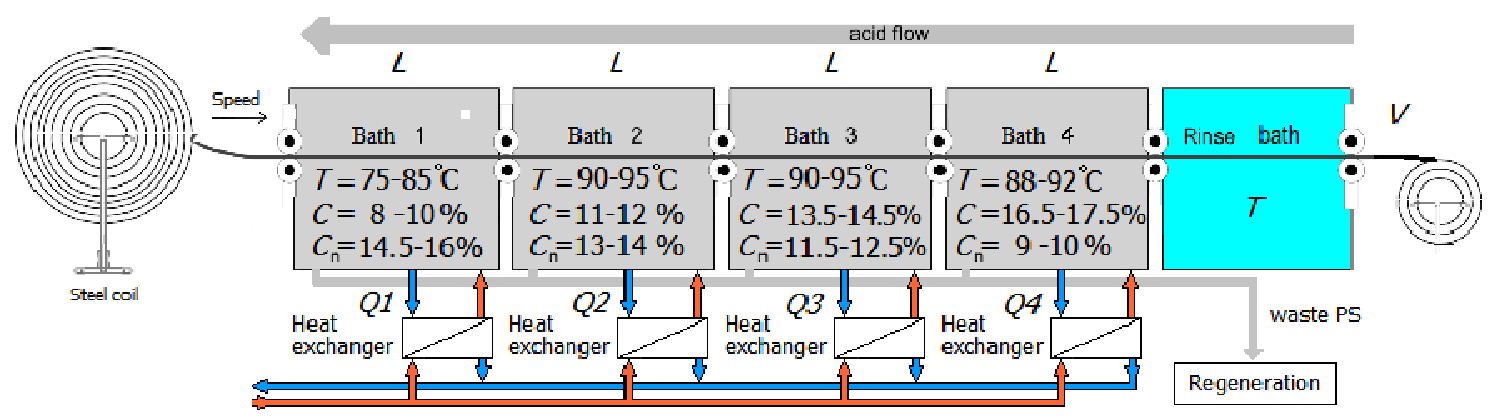

Figure 2. Principal diagram of continuous steel pickling line

The rate of the chemical reaction $(v)$ is usually considered to be the change in the concentration of the reacting substances per unit time $v=\left[C\left(t_{n+1}\right)-C\left(t_{n}\right)\right] /\left(t_{n+1}-t_{n}\right)$. At the initial moment of the reaction, the speed is always higher than in any subsequent one. During the reaction, the concentration of reagents decreases, and the rate slows down. 
The variable that has the strongest influence on TP is the temperature of the solution [29], which is directly affected by heating of $\operatorname{PS} \Delta Q_{\mathrm{T}} \rightarrow \Delta T$. The temperature dependence $v(T)$ most correctly describes the well-known Arrhenius equation. But for an approximate evaluation of the reaction rate in the interval $T=\left(0{ }^{\circ} \mathrm{C} ; 100{ }^{\circ} \mathrm{C}\right)$, the Van't Hoff empirical rule can be applied, the extended equation of which is given in [30]. The equation described this rule is as follows:

$$
v_{2}=v_{1} \times \gamma^{\frac{T 2-T 1}{10}}
$$

where $v_{1}$ is the reaction rate at a temperature $T 1\left[{ }^{\circ} \mathrm{C}\right], v_{2}$ is the reaction rate at temperature $T 1\left[{ }^{\circ} \mathrm{C}\right]$ and $\gamma$ is the temperature coefficient of reaction $(\approx 2 \div 4)$.

According to the experimental data (all ones on heat consumption and acid consumption were provided by the Chief Technologist of Mariupol Steelworks), with an increase of the PS temperature for every $10{ }^{\circ} \mathrm{C}$, the pickling reaction rate was increasing in $\approx 1.8 \div 2.4$ times, depending on the current values $C_{\mathrm{n}}, C, T$. The dwell time of steel in pickling solution $\left(t_{\mathrm{P}}\right)$ depends on $v$, which is nonlinearly related to the TP parameters $C$ and $T$, which significantly complicates the process control.

On the other hand, TP can be formalized by a typical Manufacturing Resource Planning task (MRP-II) of "replenishing reserves" [31] of thermal energy. Maintenance of the level of supply with thermal energy is provided by supplying steam to a heat exchanger with a controlled flow rate of $Q_{\mathrm{V}}(t) \leq 3.765 \mathrm{MW}$. The consumption of thermal energy in the steady state occurs at a conditionally constant rate in a fuzzy interval.

The boundaries of the interval are determined by the temperature of the steel strip at the entrance to the pickling line, by the entrainment and evaporation of the heated pickling line PS from the pickling line and by the necessity of heating the replenished to the regulated volume of the PS by a conditionally constant value of $Q_{\mathrm{C}}(t) \approx 2.893 \mathrm{MW}$.

The value of the additional heat energy flow $Q_{\mathrm{RV}}(t)$ takes into account the need to increase the temperature of the PS to maintain its activity:

$$
\frac{d Q}{d t}=Q_{\mathrm{V}}(t)-Q_{\mathrm{C}}(t)-Q_{\mathrm{RV}}(t)
$$

where $Q_{\mathrm{V}}(t) \leq 3.765 \mathrm{MW}$ is the thermal energy consumption from the heat carrier (steam).

In general, the pickling rate function can be represented as a hypersurface of the model $f\left(T, C, C_{\mathrm{n}}\right)=t_{\mathrm{P}}$ for which a set of experimental data [25] is known for a set of values $(X ; Y)$.

To ensure the process performance it is necessary to keep the condition $\frac{d Q}{d t}=Q_{\mathrm{V}}(t)-Q_{\mathrm{C}}(t)-Q_{\mathrm{RV}}(t)$. The random variable $Q_{\mathrm{RV}}(t)$ depends nonlinearly on the amount of scale that has entered the reaction and is a monotonically increasing function of time. The descaling reaction entails a decrease in the concentration of PS, which is established by the regulations (hereinafter, for simplicity, the conditions for the 1-bath are considered) in the interval $C=8-10 \%$ during the 4-hour operating cycle $(14,400 \mathrm{~s})$ until the solution is refreshed-drain and replaced with $24.0 \mathrm{~m}^{3}$ ( 0.5 of the bath volume).

To obtain analytical dependence approximating hypersurface $H\left(C, C \mathrm{n}, T, t_{\mathrm{P}}\right)$, it is advisable to construct an artificial neural network of a RBF with $m$ reference points for measuring parameters taken as centers of neurons.

The stability of the TP is ensured by using a supervisor $R_{\mathrm{AS}}$ that forms tasks to a group of independent regulators: $R_{1}: T(t), \ldots, R_{\mathrm{n}}: C(t)$. The regulators control parameters 
by parallel control loops $C_{1}, \ldots, \mathrm{C}_{\mathrm{n}}$ and correct $u_{i}$ according to the error of the TP deviation $\left(e_{i}\right)$ from the desired state of the output of TP $\left(y_{0}\right)$.

The prototype of developed process control is described in [32]. The process control principal diagram is presented on Figure 3.

The work of the modified supervisor, including all tasks of TP identification, can be described as follows. The supervisor identifies $X$, the current state of the TP. If under the influence of a perturbation $(d)$, the TP state becomes beyond certain established boundaries of the parameters $M_{x}$, it $R_{\mathrm{AS}}$ forms a task $t_{i}^{*}$ for the regulator $\left(R_{i}\right)$, which performs a stabilizing action $\left(u_{i}\right)$ to return the TP to optimal states of $M_{o}$.

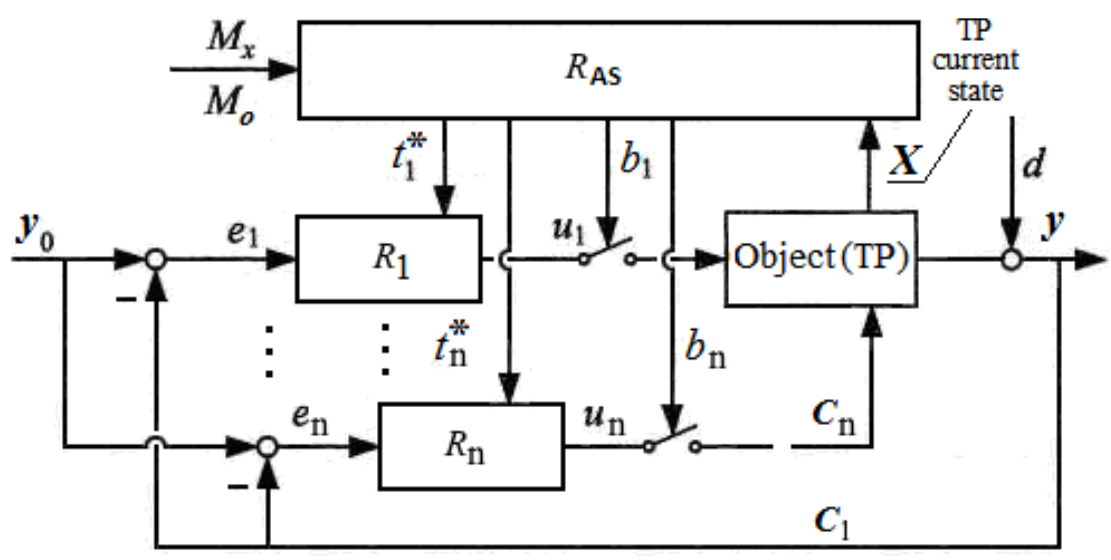

Figure 3. The principal diagram of process control

If the result of stabilizing action performance is unsatisfactory, (becomes potentially dangerous), the input control signal $\left(u_{i}\right)$ switches off. The solution of one of the tasks performed by the supervisor, namely the formation of the temperature task $T^{*}(n)$ for the TP is considered below.

\section{Model configuration}

The ability of neural networks to approximate unknown areas of the "input-output" mapping is widely used to identify objects. The properties of the radial-basic network are completely determined by the radial-basis functions $\Phi$ used in the neurons of the hidden layer and forming a certain basis for the input vector image $x$ next RBF:

$$
\phi(x)=\Phi(\|x-c\|, \sigma)=\Phi(r, \sigma)
$$

where $\phi(x)$ is a multidimensional function that depends on the distance $r=\|x-c\|$ between the input vector $x$ and its own center $c$ and the width (scale) parameter $\sigma$, that defines the local region of the input space to which the given function "reacts". Thus, each neuron of the hidden layer computes the distance between the input vector and its center and performs some nonlinear transformation $\Phi(r, \sigma)$ over it. The most widely used are Gaussian Radial Basis (GRB) functions having a peak at the center of $c$ and monotonically decreasing with distance from the center. A representation of the ANN structure that implements the mapping $R^{n} \rightarrow R^{1}$ is shown in Figure 4.

In most practical applications, node centers $\left(c_{i}\right)$ and width parameters $\left(\sigma_{i}\right)$ are fixed, and only synaptic weights $\left(w_{i}\right)$ are tuned.

Complex objects are modeled using a multidimensional Gaussian:

$$
\phi(x)=\Phi(\|x-c\|, \Sigma)=\exp \left[-(x-c)^{T} \Sigma^{-1}(x-c)\right]=\exp \left(-\|x-c\|_{\Sigma^{-1}}^{2}\right)
$$


where the covariance matrix $\Sigma$ determines the shape, size and orientation of the so-called receptor field of the radial-basis function. At $\Sigma=\operatorname{diag}\left(\sigma_{1}^{2}, \sigma_{2}^{2}, \ldots, \sigma_{\mathrm{n}}^{2}\right)$ is a hyper ellipsoid whose axes coincide with the axes of the input space and have a length $2 \sigma_{i}$ of the $i$-th axis.

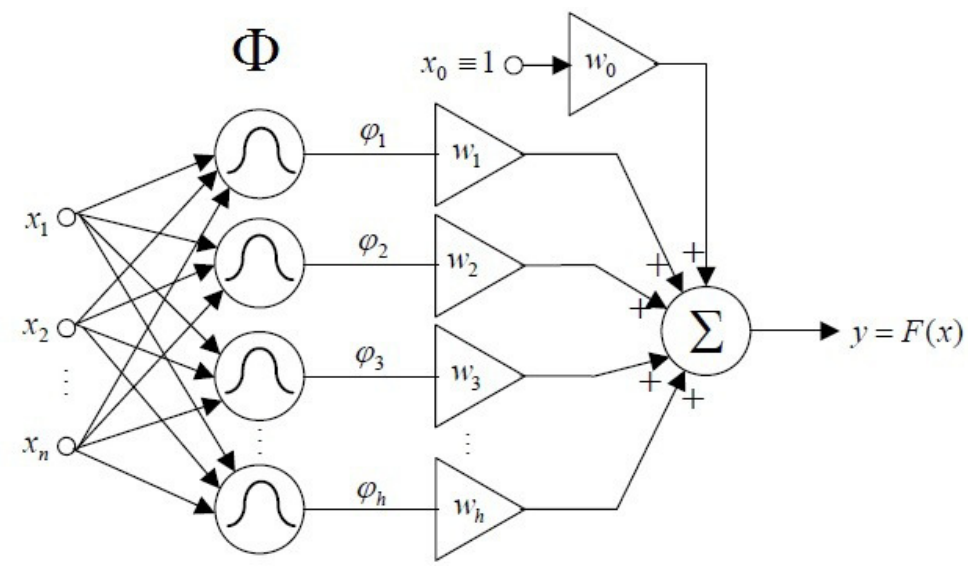

Figure 4. RBFN realizing the mapping $y=F(x)=w_{0}+\sum_{i=1}^{h} w_{i} \phi_{i}(x)$

A typical example that demonstrates the possibilities of radial-basis networks is the interpolation problem for a multidimensional function of $n$ variables defined on $N$ points $x(1), x(2), \ldots, x(k), \ldots, x(N)$. The corresponding values of this function are known: $d(1), d(2), \ldots, d(k), \ldots, d(N)$. The problem consists in a mapping satisfying interpolation conditions definition:

$$
F[x(k)]=d(k), k=1,2, \ldots, N
$$

The radial-basis technique in this case consists in choosing the following function $F$ :

$$
F(x)=\sum_{k=1}^{N} w_{k} \Phi_{k}\left(\left\|x-c_{k}\right\|, \sigma_{k}\right)=\sum_{k=1}^{N} w_{k} \Phi_{k}\left(\|x-x(k)\|, \sigma_{k}\right)
$$

where $\Phi$ is a radial-basis function, the centers of which are points $x(k)$. With allowance for eq. (5) and eq. (6), we can write a system of linear equations for finding the coefficients (synaptic weights) $w_{k}$ :

$$
\left(\begin{array}{cccc}
\Phi_{11} & \Phi_{12} & \cdots & \Phi_{1 N} \\
\Phi_{21} & \Phi_{22} & \cdots & \Phi_{2 N} \\
\vdots & \vdots & \ddots & \vdots \\
\Phi_{N 1} & \Phi_{N 2} & \cdots & \Phi_{N N}
\end{array}\right)\left(\begin{array}{c}
w_{1} \\
w_{2} \\
\vdots \\
w_{N}
\end{array}\right)=\left(\begin{array}{c}
d(1) \\
d(2) \\
\vdots \\
d(N)
\end{array}\right)
$$

where $\Phi_{k j}=\Phi\left[\|x(j)-x(k)\|, \sigma_{k}\right] ; k=1, \ldots, N ; j=1, \ldots, N$.

Denoting $d=[d(1), d(2), \ldots, d(N)]^{T}, w=\left(w_{1}, w_{2}, \ldots, w_{N}\right)^{T}, \Phi=\left\{\Phi_{k j}\right\}$, get:

$$
\Phi w=d
$$

wherefrom: 


$$
w=\Phi^{+} d
$$

where $\Phi^{+}$is a pseudo inverse matrix to $\Phi$.

RBF nets are the universal approximators and because only one nonlinear hidden layer is present, the parameters of the linear output layer are the subject of adjustment with standard procedures [16]. High speed and filtering properties may be used for their training, which is very useful when processing the "noisy" measurements.

A non-linear input-output mapping may be described by the relation:

$$
d=f(x)
$$

where $x-(n \times 1)$ is input vector, $d$ is output, $f(x)$ is unknown vector-function, which is evaluated with the help of training sample $\{x(k), d(k)\}, k=1,2, \ldots N$.

The task of learning the approximating neural network is to find a function $F(x)$ so close $f(x)$ to that:

$$
\|F(x)-f(x)\| \leq \varepsilon, \forall x(k): k=1,2, \ldots N
$$

where $F(x)$ is the mapping realized by the network, $\varepsilon$ is a small positive number, that determines the accuracy of the approximation. In this context, the problem of approximation completely coincides with the problem of "training with the teacher" or supervised learning, where the sequence plays the role of the ANN input signal, and $f(x)$ is the training signal (Figure 5).

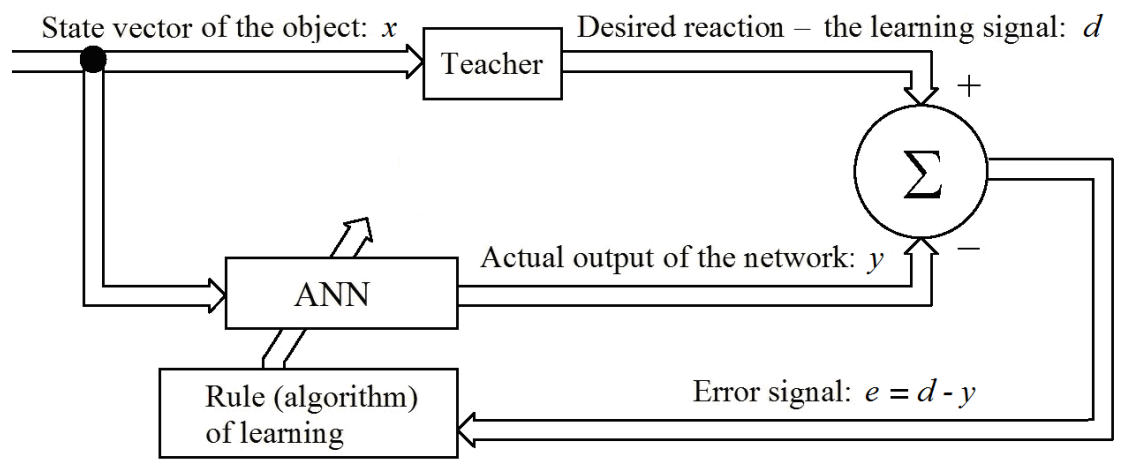

Figure 5. Supervised learning scheme

As a rule the process of building a model is divided into two stages: structural and parametric identification, and the application of the ANN also requires solving two problems: determining the network structure and setting (training) its parameters.

Usually, a change in the network structure is made by its gradual complication by adding new neurons, performed each time when an additional identification error $e=d-y$ occurs when a new input signal appears, exceeding the permissible one. Training (parametric identification) consists in determining the network parameters and reduces to minimizing the identification error - as a rule, a quadratic error functional:

$$
J(k)=\|\varepsilon(k)\|^{2}=\|d(k)-y(k)\|^{2}
$$

In practice, the most common are discrete learning algorithms of the form:

$$
w_{j i}(k+1)=w_{j i}(k)+\eta(k) e_{j}(k) x_{i}(k)
$$


or in vector form:

$$
w_{j}(k+1)=w_{j}(k)-\eta_{k} \nabla_{w j} E_{j}(k)=w_{j}(k)+\eta(k) e_{j}(k) x_{i}(k)
$$

where $\nabla_{w_{j}} E_{j}(k)=-e_{j}(k) x_{i}(k)$ is the gradient vector of the objective function by the synaptic weights. The speed of the learning process using the eq. (13) and eq. (14) is completely determined by the choice of the parameter $\eta_{k}$ that determines the step of the displacement in the space of the tunable parameters. It is natural to choose this parameter so that the rate of convergence of the current values $w_{j}(k)$ to the optimal hypothetical weights will be maximal. Introducing into consideration, the vector of deviations of the current values $w_{j}(k)$ from the optimal values in the form:

$$
\tilde{w}_{j}(k)=w_{j}-w_{j}(k)
$$

and the differential equation solution:

$$
\frac{\partial\left\|\tilde{w}_{j}(k)\right\|^{2}}{\partial \eta}=0
$$

the optimal value of the step parameter may be obtained in the form:

$$
\eta(k)=\|x(k)\|^{-2}
$$

that leads to a one-step learning algorithm:

$$
w_{j}(k+1)=w_{j}(k)+\frac{e(k) x(k)}{\|x(k)\|^{2}}
$$

Eq. (18) is known in the theory of artificial neural networks [33] as the Kaczmarz-Widrow-Hoff algorithm.

The cut of the model $H\left(C, C_{\mathrm{n}}, T, t_{\mathrm{P}}\right)$, reduced by the setting pickling rate $t_{\mathrm{P}}^{*}=$ const identifies the temperature necessary to ensure the given process speed at the current varying values of the parameters, and transmits in the $k$-th moment of discrete time as the value for the regulator flow rate of the coolant value $T^{*}(k)=f^{T}\left[C_{1}(k), C_{\mathrm{n}}(k), t_{P}^{*}\right]$.

When constructing a neural RBF net for each of the $m$ neurons, the GRB-function of activation is determined:

$$
y=f(X)=y_{0} \exp \left\{-\sum_{i=1}^{3} \frac{\left(x_{i}-c_{i}\right)^{2}}{2 \delta_{i}^{2}}\right\}
$$

\section{RESULTS}

Experimental studies had shown the follows: for maximal strip feed rate of $2 \mathrm{~m} / \mathrm{s}$ for steel rolls, and full cleaning of the steel strip surface completely coated with scale in the picking process, the decrease in solution concentration was $C \leq 2.788 \times 10^{-4} \%$ per second (here and below, for simplicity, only the data for the first bath are considered). PS heating by approximately $0.02 \times Q_{\mathrm{C}} \approx 0.0578 \mathrm{MW}$ compensates decreasing of PS concentration of the PS by $C=2.788 \times 10^{-4} \%$ per second and ensures the stabilization of the process rate. 
The value $Q_{\mathrm{RV}}(t)$ is random, limited by the interval: $0 \leq Q_{\mathrm{RV}} \leq 0.02 \times Q_{\mathrm{C}}$, and brings its share of uncertainty into TP.

In general, the pickling rate function can be represented as a hyper surface of the model $t_{\mathrm{P}}=f\left(T, C, C_{\mathrm{n}}\right)$ for which a set of experimental data is known for a set of values $(X ; Y)$. The model should determine the optimal operational control effects on the process under routine constraints and maintain a constant pickling rate for a given level. The structure of the neural network identification model with calculated weight coefficients at all layers (inputs: hidden layer nodes: output) is 3:16:1, respectively, is shown at Figure 6.

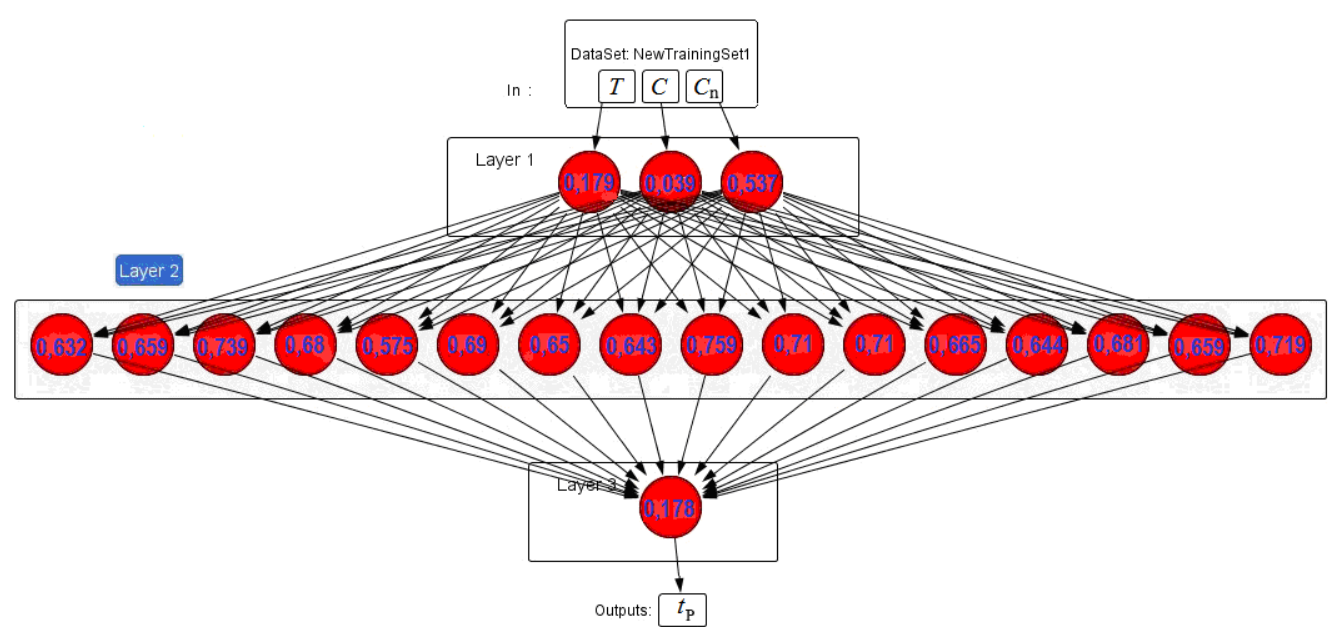

Figure 6. The identification model structure

The validation of the neural network model shows that the set accuracy $5 \times 10^{-4}$ is the maximal difference between real values $t_{\mathrm{P}}$ from set of training tuples $\left(t_{\mathrm{P}}, T, C, C_{\mathrm{n}}\right)$ and values $t_{\mathrm{P}}^{*}$, calculated according to model, is achieved at the 809 learning iteration (Figure 7). On the sample of the experimental data, taking into account the recommendations given in [33], the centers and values of branch coverage were adjusted by "training with the teacher" [34]. The package Neuroph Studio automatically corrects the parameters (expected values $\mu_{i}$ and variances $\sigma_{i}$ ) of functions $G_{i}(\mu, \sigma), i=1, \ldots, N$ in layer 2 when the structure of the model (value $N$ ) is changed.

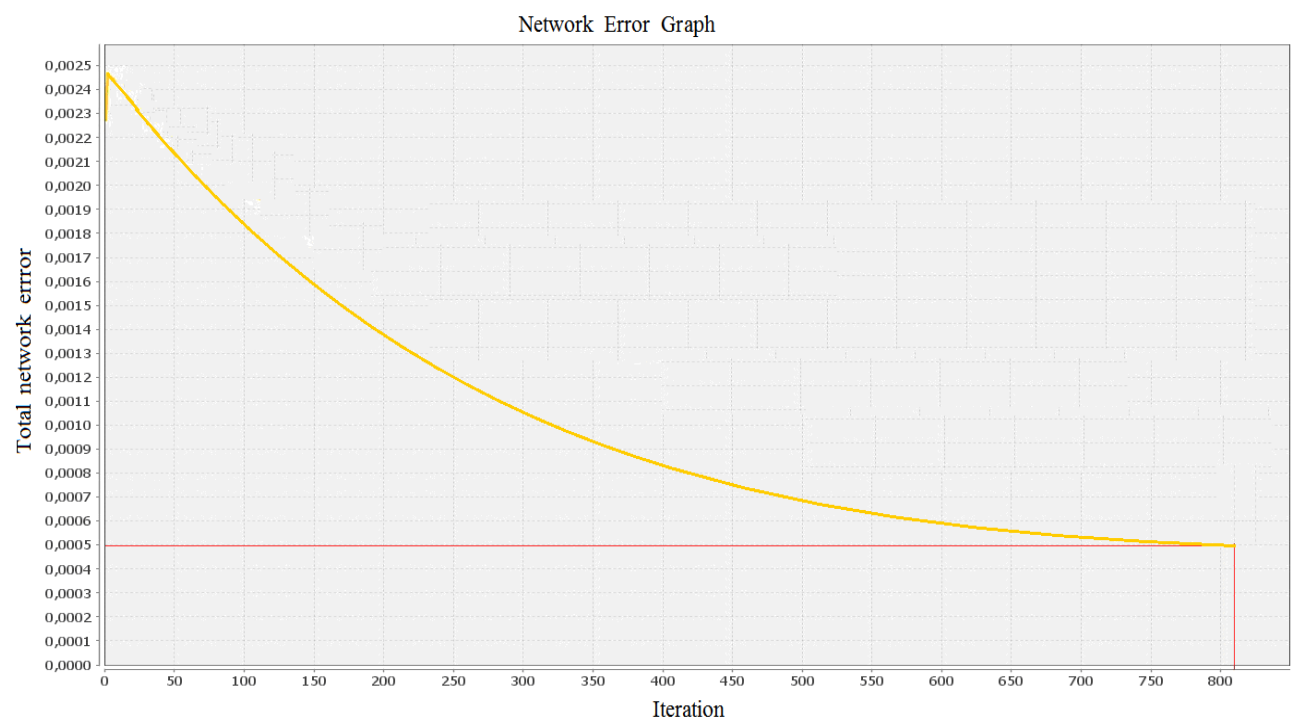

Figure 7. The validation of the RBFN model 
The obtained RBF-network determines the optimal strategies for metal pickling TP under the constraints of the parameters pairs $(T, C)$, and maintains the pickling rate at a required level (Figure 8). Particularly, for the required $t_{\mathrm{P}}^{*}=38 \mathrm{~s}$ and given $C_{\mathrm{n}}=0 \%$, the set of optimal parameters pairs $(T, C)$ is located on the red curve (Figure $8 \mathrm{a}$ ). So, when the concentration is reduced from $10 \%$ to $8 \%$, the optimum temperature of the TP will be $T^{*}=93^{\circ} \mathrm{C}$.

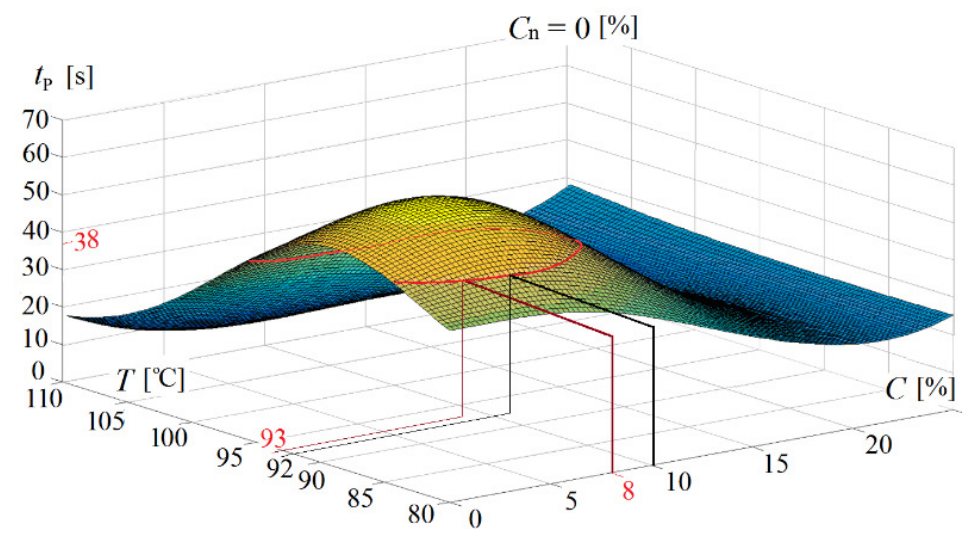

(a) $80{ }^{\circ} \mathrm{C}<T, C<25 \%, C_{\mathrm{n}}=0 \%$

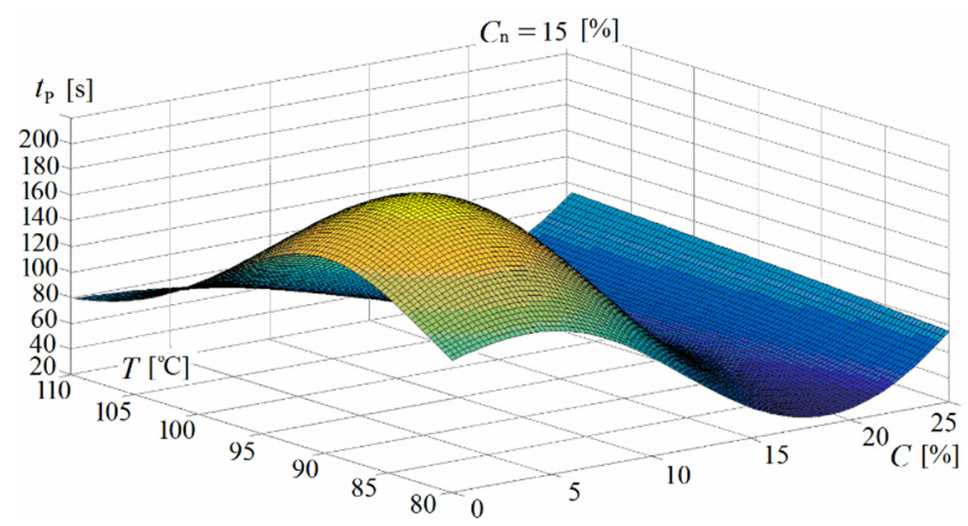

(b) $80{ }^{\circ} \mathrm{C}<T, C<25 \%, C_{\mathrm{n}}=15 \%$

Figure 8. Fragments of model $t_{\mathrm{P}}=f\left(T, C, C_{\mathrm{n}}\right)$

When there are no restrictions on consumption of thermal energy and acid, in order to determine the optimal values $\left(T^{*}, C^{*}\right)$ (from economical viewpoint), it is necessary to solve the optimization problem [31]:

$$
B_{1} \times \Delta T+B_{2} \times \Delta C \rightarrow \min
$$

where $B_{1}$ is the specific cost for heat consumption and $B_{2}$ is the specific cost for acid consumption.

The proposed TP strategy optimization for pickling of cold-rolled steel allows to gradually increase the liquor temperature in the baths to the maximum limit specified by the process regulations (from $88^{\circ} \mathrm{C}$ to $95^{\circ} \mathrm{C}$ ), which compensates the declining of sulfuric acid concentration $C$.

Figure 9 shows the graphs of an example of the consumption of heat energy for a working shift: $Q_{\mathrm{b}}$ is before the heating management system of the pickling solution is modernized and $Q_{\mathrm{rbn}}$ is after applying the identification radial-basis network of TP optimal parameters, respectively. 
According to the results of a series of model experiments, the time of formation by the model of $0.15 \mathrm{~s}$, and this value can be neglected taking into account the inertness of the heating system [27].

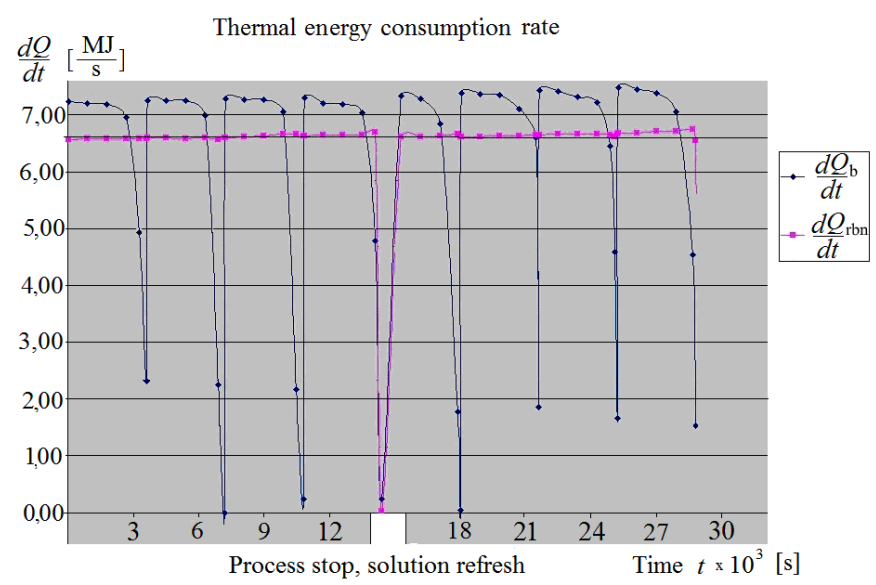

Figure 9. Graphs of the heat energy consumption

As a result of the task, $T^{*}(k)$ is the temperature of the solution required at the moment $(k)$, did not exceed the application of the developed neural network, steam consumption for pickling process was reduced from 7.246 MW to 6.700 MW, acid consumption for pickling process was reduced by $26 \%$ : from 1,230 to $976 \mathrm{~kg} / \mathrm{h}$, while maintaining the same efficiency of pickling line. Accordingly, the load on the technical water purification from the sludge and the regeneration of sulfuric acid decreased by $26 \%$, and the consumption of industrial water for preparation of the pickling solution.

Figure 10 shows the graphs of sulfuric acid mass consumption rate for the work shift $G_{\mathrm{b}}$, before the application of the identification RBFN model, and $G_{\mathrm{rbn}}$, after.

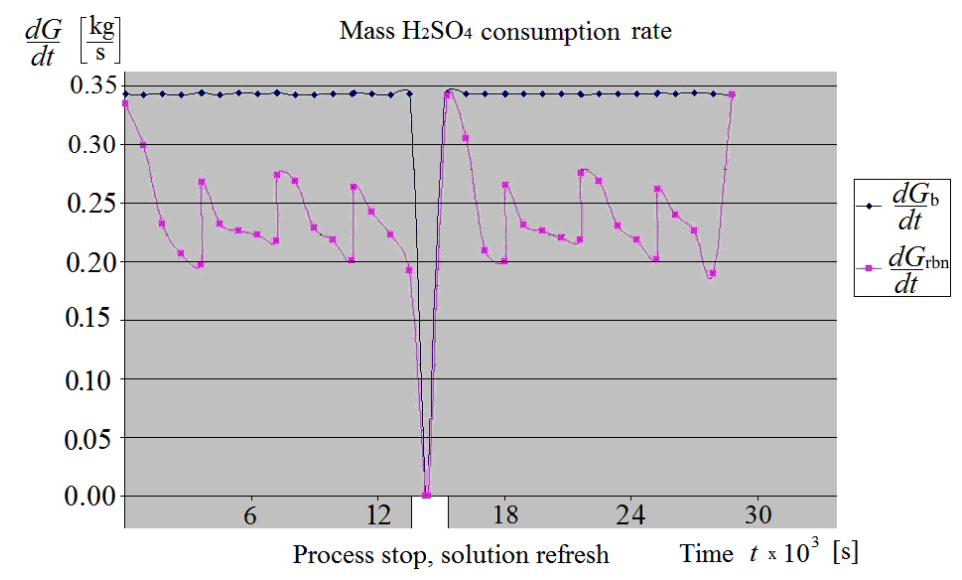

Figure 10. Graphs of sulfuric acid consumption

\section{DISCUSSIONS}

The proposed model is considered static because of the low speed of process control, and realizes the operational identification of the optimum $T^{*}$ value, forming the current task for the controller of the coolant flow. One of the criteria for quality control TP is the surface purity coefficient, which in general form can be represented as:

$$
q_{e}=\frac{\sum S_{i}^{\text {out }} d_{i}}{\sum S_{j}^{\text {in }} d_{j}}
$$


where $S_{i}^{\text {out }}$ is the area of the $i$-th classes defects with the thickness $\left(d_{i}\right)$ at the output of the $\mathrm{TP}, S_{j}^{\text {in }}$ is the area of the $j$-th classes defects with the thickness $\left(d_{j}\right)$ at the input to the TP.

Exceeding $q_{\mathrm{e}}$, the set value $\delta_{\mathrm{q}}$ during a certain time period of the specified observation window $[t(k) ; t(k+10)]$, indicates the need for changes in training rules and parameters of the identification model for correcting the values of the output values of the parameter $T^{*}$, tasks for the coolant flow controller.

Taking into account that the reaction time for PS heating is large enough, a separate interest is represented by the GRNN-model of the form: $T^{*}(k)=f\left[C(k-1), C_{\mathrm{n}}(k-1), C(k), C_{\mathrm{n}}(k), T^{*}(k-1), q_{\mathrm{e}}(k)\right]$ at a set $t_{\mathrm{P}}$.

To construct such a model, the input vector $X$ must be supplemented with process state variables at the previous cycles.

The future research may be focused on extended MIMO-model $\left(C^{*}, T^{*}\right)=f\left(C, C_{\mathrm{n}}, q_{\mathrm{e}}\right)$, which will provide an additional opportunity to identify the status of the PS and the formation of operational tasks for concentration $\left[C^{*}(k)\right]$ and temperature $\left[T^{*}(k)\right]$.

MIMO-model is of practical interest when is used with the cost criterion. The cost criterion of operational parameter management $C C_{\mathrm{OPM}}$ is proposed to be reduced to a value scale in a simplified additive form by introducing a scalar of specific coefficients of unit $\operatorname{costs} B$ of the change of each of the controlled parameters $\Delta X$, and has the form:

$$
C C_{\mathrm{OPM}}=\left\{\begin{array}{l}
\arg \min t_{\mathrm{P}} \\
\frac{X}{\text { for } \quad B_{1} \times \alpha_{1} \times \Delta T+B_{2} \times \alpha_{2} \times \Delta C+B_{3} \times \alpha_{3} \times \Delta C_{\mathrm{n}} \rightarrow \min }
\end{array}\right.
$$

Values of weighting coefficients $\alpha_{i}$ can be estimated by expert procedure with clustering of factors of influence of parameters on TP, described in [35].

\section{CONCLUSIONS}

The RBFN $H\left(C, C_{\mathrm{n}}, T, t_{\mathrm{P}}\right)$ of the pickling process identification, using GRB activation functions is designed. At each discrete $k$-moment of TP time $t(k)$ RBFN forms the optimal current temperature task $T^{*}(k)$ for the pickling solution flow controller in order to minimize the energy consumption and reduce the consumption of fresh acid, maintain the pickling solution and stabilize the process speed. The proposed management strategy leads to a reduction in the consumption of sulfuric acid, water for acid regeneration, thermal energy and, accordingly, harmful emissions and waste of TP.

The modified supervisor, which identifies the current state of the TP and forms tasks for regulators in each discrete moment of TP, is presented.

The surface purity coefficient as one of the criteria for quality control TP is described.

Such approach may be used for continuous pickling lines with hydrochloric acid pickling process and for stainless steel pickling lines with remote heat exchangers for solution heating. RBF -models could be used successfully in the process control of multivariable TP and systems.

\section{NOMENCLATURE}

$B_{1} \quad$ specific cost for heat consumption

$\left[\mathrm{UAH} /{ }^{\circ} \mathrm{C}\right]$

$B_{2} \quad$ specific cost for acid consumption

[UAH/\%]

$B_{3} \quad$ specific cost for pickling solution refreshing

[UAH/\%]

$C \quad$ concentration of pickling solution

$C_{\mathrm{n}}$

monotonic non-decreasing time function of Iron(II) sulfate

$[\mathrm{g} / \mathrm{L}]$ 
$\left(\mathrm{FeSO}_{4}\right)$ salt concentration change in pickling solution

$C C_{\text {OPM }}$ cost criterion of operational parameter management

$[\mathrm{UAH}]$

$d_{i} \quad$ thickness of the $i^{\text {th }}$ class defect

$G(t) \quad$ controlled sulfuric acid mass consumption

$[\mathrm{kg}]$

$q_{\mathrm{e}} \quad$ surface purity coefficient

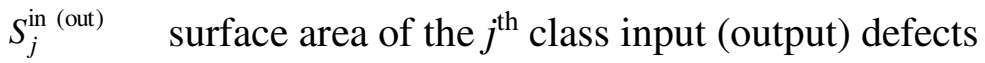

[sq $\mathrm{mm}]$

$T \quad$ temperature of the pickling solution

$\left[{ }^{\circ} \mathrm{C}\right]$

$t_{\mathrm{P}} \quad$ dwell time of steel strip in pickling solution

[s]

$t \quad$ time

$[\mathrm{s}]$

\section{Greek letters}

$\delta_{\mathrm{q}} \quad$ set limit of surface purity coefficient

$\varepsilon \quad$ satisfactory accuracy of approximating radial basis function network

$v \quad$ rate of the chemical reaction

$\Delta Q_{\mathrm{T}} \quad$ controlled thermal energy

\section{Abbreviations}

ANN Artificial Neural Network

EPA United States Environmental Protection Agency

GRB Gaussian Radial Basis Function

PS Pickling Solution

RBF Radial Basis Function

RBFN Radial Basis Function Network

TP Technological Process

UAH Ukrainian Hryvna

\section{REFERENCES}

1. Environmental Protection Agency, Sulfuric Acid and Ferrous Sulfate Recovery from Waste Pickling Liquor, EPA Technology Transfer Capsule Report, EPA-660/2-73-032, 82 p, Washington D. C., USA, 1978.

2. Himmelblau, D. M., Application of Artificial Neural Networks in Chemical Engineering, Korean Journal of Chemical Engineering, Vol. 17, No. 4, pp 373-392, 2000, https://doi.org/10.1007/BF02706848

3. Fei, H., Min, L. and Baojian, W., Multi-mode Acid Concentration Prediction Models of Cold-rolled Strip Steel Pickling Process, Journal of Process Control, Vol. 24, No. 6, pp 916-923, 2014, https://doi.org/10.1016/j.jprocont.2014.04.007

4. Gitifar, V., Eslamloueyan, R. and Sarshar, M., Experimental Study and Neural Network Modeling of Sugarcane Bagasse Pretreatment with $\mathrm{H}_{2} \mathrm{SO}_{4}$ and $\mathrm{O}_{3}$ for Cellulosic Material Conversion to Sugar, Bioresource Technology, Vol. 148, pp 47-52, 2013, https://doi.org/10.1016/j. biortech.2013.08.060

5. Behroozi-Khazaei, N. and Nasirahmadi, A., A Neural Network Based Model to Analyze Rice Parboiling Process with Small Dataset, Journal of Food Science and Technology, Vol. 54, No. 8, pp 2562-2569, 2017, https://doi.org/10.1007/s13197-017-2701-x

6. Singh, A. K., Singh, H. P. and Sachin, M., Validation of ANN-Based Model for Binary Distillation Column (Singh, R. and Choudhury, S., eds.), Proceedings of International Conference on Intelligent Communication, Control and Devices, Advances in Intelligent Systems and Computing, Singapore, Republic of Singapore, 2017, https://doi.org/10.1007/978-981-10-1708-7_27

7. Tarafdar, A., Shahi, N. C., Singh, A. and Sirohi, R., Artificial Neural Network Modeling of Water Activity: A Low Energy Approach to Freeze Drying, Food and Bioprocess 
Technology Vol. 11, No. 1, pp 164-171, 2018, https://doi.org/10.1007/s11947-017-2002-4

8. Asnaashari, E., Asnaashari, M., Ehtiati, A. and Farahmandfar, R., Comparison of Adaptive Neuro-fuzzy Inference System and Artificial Neural Networks (MLP and RBF) for Estimation of Oxidation Parameters of Soybean Oil Added with Curcumin, Journal of Food Measurement and Characterization, Vol. 9, No. 2, pp 215-224, 2015, https://doi.org/10.1007/s11694-015-9226-7

9. Anastácio, A., Silva, R. and Carvalho, I. S., Phenolics Extraction from Sweet Potato Peels: Modelling and Optimization by Response Surface Modelling and Artificial Neural Network, Journal of Food Science and Technology, Vol. 53, No. 12, pp 4117-4125, 2016, https://doi.org/10.1007/s13197-016-2354-1

10. Vasseghian, Y., Ahmadi, M. and Joshaghani, M., Ultrasound Assisted Ash and Sulphur Removal from Bitumen Using Column Flotation Technique: Experimental, RSM and ANN Methods in Modelling and Optimization of Process, Iranian Journal of Science and Technology, Transactions A: Science, Vol. 41, No. 4, pp 1149-1163, 2017, https://doi.org/10.1007/s40995-016-0068-x

11. Guo, W., Shang, L., Zhu, X. and Nelson, S. O., Nondestructive Detection of Soluble Solids Content of Apples from Dielectric Spectra with ANN and Chemometric Methods, Food and Bioprocess Technology, Vol. 8, No. 5, pp 1126-1138, 2015, https://doi.org/10.1007/s11947-015-1477-0

12. Daosud, W., Neural Networks for Chemical Process, Asia-Pacific Journal of Science and Technology (APST) (in Thai), Vol. 19, No. 1, pp 161-179, 2014.

13. Hussain, M. A., Review of the Application of Neural Networks in Chemical Process Control-simulation and Online Implementation, Artificial Intelligence in Engineering, Vol. 13, No. 1, pp 55-68, 1999, https://doi.org/10.1016/S0954-1810(98)00011-9

14. Henson, M. A., Nonlinear Model Predictive Control: Current Status and Future Directions, Computers and Chemical Engineering, Vol. 23, No. 2, pp 187-202, 1998, https://doi.org/10.1016/S0098-1354(98)00260-9

15. Kittisupakorn, P., Nueaklong, E. and Daosud, W., NN-Based MPC for Heat Exchanger System in Hard Chrome Electroplating, International Journal of Applied Biomedical Engineering, Vol. 7, No. 3, pp 21-27, 2014.

16. Fan, M., Hu, J., Cao, R., Xiong, K. and Wei, X., Modeling and Prediction of Copper Removal from Aqueous Solutions by $\mathrm{nZVI} / \mathrm{rGO}$ Magnetic Nanocomposites using ANN-GA and ANN-PSO, Scientific Reports, Vol. 7, No. 1, 2017, https://doi.org/10.1038/s41598-017-18223-y

17. Zhang, F., Zhan, P., Tian, H., Wei, Z. and Wang, P., Optimization of HS-SPME using Artificial Neural Network and Response Surface Methodology in Combination with Experimental Design for Determination of Volatile Components by Gas Chromatography-Mass Spectrometry in Korla Pear Juice, Food Analytical Methods, Vol. 11, No. 8, pp 2218-2228, 2018, https://doi.org/10.1007/s12161-018-1173-6

18. Kittisupakorn, P., Thitiyasook, P., Hussain, M. A. and Daosud, W., Neural Network Based Model Predictive Control for a Steel Pickling Process, Journal of Process $\begin{array}{llllll}\text { Control, Vol. 19, No. 4, pp 579-590, } & \text { 2009, }\end{array}$ https://doi.org/10.1016/j.jprocont.2008.09.003

19. Psichogios, D. C. and Ungar, L. H., Direct and Indirect Model Based Control using Artificial Neural Networks, Industrial and Engineering Chemistry Research, Vol. 30, No. 12, pp 2564-2573, 1991, https://doi.org/10.1021/ie00060a009

20. Hussain, M. A., Neural Network Techniques and Application in Chemical Process Control System (Leondes, C. T., ed.), Vol. 5, pp V327-V360, CRC Press, Boca Raton, Florida, USA, 2003.

21. Golden, R. M., Mathematical Methods for Neural Network Analysis and Design, MIT Press, Cambridge, Massachusetts, USA, 1996. 
22. Hussain, M. A., Ho, P. Y. and Allwright, J. C., Adaptive Linearizing Control with Neural Network Based Hybrid Models, Industrial and Engineering Chemistry Research, Vol. 40, No. 23, pp 5604-5620, 2001, https://doi.org/10.1021/ie000919r

23. Katsumi, M., Picкling Plant and Method of Controlling the Same, Patent US №6096137 B08B 1/02, B08B 3/08, p 22, 2000.

24. Hasler, F., The Whys and Hows of Sulfuric Acid Pickling and Recovery, Esco Engineering, Ontario, Kingsville, Canada, 1995, http://pas.mnsi.net/wh\%20sulfuric\%20rev05.pdf, [Accessed: 21-September-2018]

25. Gakhov, R. P., Ilyunin, O. O. and Shamraev, A. A., Neuro-fuzzy Control of Continious Steel Strip Pickling (in Russian), Research Result, Vol. 1, No. 2, pp 52-59, 2016, https://doi.org/10.18413/2518-1092-2016-1-2-52-59

26. Piegat, A., Fuzzy Modeling and Control, Physica-Verlag, Springer-Verlag Company, Heidelberg, Germany, 2001.

27. European Commission, Reference Document on Best Available Techniques for the Ferrous Metals Processing Industry, p 538, 2001.

28. Kapustenko, P. A., Perevertaylenko, A. Y., Khavin, G. L. and Arsenyeva, O. P., Graphite Plate Heat Exchangers as Energy Saving Tool for Corrosive Media Duties, Chemical Engineering Transactions, Vol. 12, pp 219-224, 2007.

29. Levine, I. N., Physical Chemistry (6 ${ }^{\text {th }}$ ed.), McGraw-Hill Companies Inc., New York, USA, 2009.

30. Lone Jr., I. H., The Extended Van't Hoff Equation \& its Significance, American Journal of Applied and Industrial Chemistry, Vol. 3, No. 4, pp 46-48, 2017, https://doi.org/10.11648/j.ajaic.20170304.12

31. West Churchman, C., Introduction to Operations Research, John Wiley \& Sons Inc., New Jersey, USA, 2009.

32. Wang, L. X., A Supervisory Controller for Fuzzy Control Systems that Guarantees Stability Analysis, Englewood Cliffs, Prentice Hall, New Jersey, USA, 2004.

33. Nelles, O., Nonlinear System Identification, Springer Verlag, Berlin, Germany, 2000.

34. Kaczmarz, S., Approximate Solution of Systems of Linear Equations, Int. J. Control., Vol. 57, No. 6, pp 1269-1271, 1993, https://doi.org/10.1080/00207179308934446

35. Boldyryev, S., Garev, A., Ilunin, O., Shamraev, A., Selyakov, O., Leshchenko, O. and Kapustenko, P., Modified Criterion for Economic Efficiency Estimation of Heat Pumps, Chemical Engineering Transactions, Vol. 35, pp 475-481, 2013, https://doi.org/10.3303/CET1335079 